\title{
miR-210-3p regulates the proliferation and apoptosis of non-small cell lung cancer cells by targeting SIN3A
}

\author{
JIE REN ${ }^{1}$, XIAODAN LI ${ }^{1}$, HAO DONG ${ }^{2}$, LONGLONG SUO $^{1}$, JUN ZHANG $^{3}$, LINA ZHANG $^{4}$ and JING ZHANG $^{4}$ \\ ${ }^{1}$ Department of Clinical Surgery, Handan First Hospital, Handan, Hebei 056002; ${ }^{2}$ Department of Orthopedic Trauma, \\ Zibo Central Hospital, Zibo, Shandong 255000; ${ }^{3}$ Department of Radiology, Leling People's Hospital, Leling, \\ Shandong 253600; ${ }^{4}$ Department of Oncology, Zibo Central Hospital, Zibo, Shandong 255000, P.R. China
}

Received May 31, 2017; Accepted June 29, 2018

DOI: $10.3892 /$ etm.2019.7867

\begin{abstract}
Previous studies have indicated that microRNA (miR)-210-3p is upregulated in NSCLC, however, the specific mechanism underlying the role of miR-210-3p in NSCLC pathogenesis requires further investigation. The aim of the present study was to explore the roles of miR-210-3p in NSCLC and the associated mechanisms. A total of 30 NSCLC tissues and paired adjacent normal tissues were collected for study. Reverse transcription-quantitative polymerase chain reaction was performed to compare the expression of miR-210-3p in the 30 paired cancerous and adjacent normal tissues. Additionally, the expression of miR-210-3p in different NSCLC lines and normal human lung epithelial cell line BEAS-2B were also compared. Furthermore, A549 and H1299 NSCLC cells were cultured and transfected with miR-210-3p inhibitors, and MTT and propidium iodide/annexin V assays were performed to investigate the effects of miR-210-3p inhibition on the proliferation and apoptosis of the cells. RT-qPCR and western blot analyses were also performed to determine the effects of miR-210-3p on the expression levels of SIN3A, B-cell lymphoma 2 (Bcl-2) and Caspase-3. Finally, a reverse experiment was conducted by transfecting A549 cells with miR-210-3p inhibitor and SIN3A small interfering (si)RNA, and a dual-luciferase reporter assay was performed to confirm that SIN3A is a direct target of miR-210-3p. It was observed that miR-210-3p was significantly upregulated in NSCLC tissues compared with the levels in the adjacent normal tissues, and that the expression of miR-210-3p in patients with NSCLC was negatively correlated with the expression of SIN3A in NSCLC tissue. miR-210-3p was also significantly upregulated in different NSCLC cell lines compared with the levels in BEAS-2B cells. The transient downregulation of
\end{abstract}

Correspondence to: Dr Jing Zhang, Department of Oncology, Zibo Central Hospital, 54 West Youth League Road, Zibo, Shandong 255000, P.R. China

E-mail: zhangjingzb@outlook.com

Key words: microRNA-210-3p, non-small cell lung cancer, SIN3A, proliferation, apoptosis
miR-210-3p in A549 cells led to a significant suppression of cell proliferation and markedly increased cell apoptosis, as well as increased the expression of SIN3A and Caspase-3 and decreased the expression of Bcl-2. On the other hand, co-transfection of miR-210-3p inhibitor and SIN3A siRNA partially blocked miR-210-3p inhibitor-induced pro-apoptotic effects. The results of the dual-luciferase reporter assay demonstrated that SIN3A is a direct target of miR-210-3p. Collectively, these findings indicate that can regulate the proliferation and apoptosis of NSCLC cells by targeting SIN3A. These results suggest that miR-210-3p has the potential to become a novel therapeutic target for the treatment of NSCLC.

\section{Introduction}

Lung cancer is one of the most common malignancies and the leading cause of cancer-related mortality every year worldwide (1). Multiple risk factors, including environmental deterioration, smoking, exposure to radon and the overexpression or mutation of certain key proteins (for example, epidermal growth factor receptor) may contribute to the occurrence and development of the disease (2-4). Due to the heterogeneity of the disease, the lack of early diagnostic markers and the high recurrence rate ( $\sim 50 \%$ of cases), the therapeutic efficacy of current anti-lung cancer therapies remains unsatisfactory (5), the therapeutic efficacy of current anti-lung cancer therapies, including surgical resection, radiotherapy and chemotherapy remain unsatisfactory, and the prognosis for patients with lung cancer is poor (5-year survival rate, <16\%) (6,7). Although lung cancer is divided into various subtypes, non-small cell lung cancer (NSCLC) is the most common, accounting for $>85 \%$ of cases (8) NSCLC can be classified into three subtypes, including adenocarcinoma, squamous cell carcinoma and large cell carcinoma. In recent years, efforts have been made to explore the pathogenesis of NSCLC (9-12); however, the mechanism underlying the carcinogenesis and development of NSCLC remains poorly understood. Elucidating the molecular mechanisms involved in NSCLC may help researchers to identify effective therapeutic targets, and also provide novel biomarkers for the risk assessment and early diagnosis of NSCLC (13).

In recent years, the roles of non-coding RNA in various diseases have become a hot topic among scientists and 
physicians. MicroRNA (miR) are a group of small, non-coding RNA that may negatively regulate the expression of their target genes (14). Abnormal behaviors of miR in various types of cancer have been observed, and the roles of $\mathrm{miR}$ as tumor suppressors or oncomiR have been reported previously (15-17). miR-210 has been demonstrated to serve important roles in a variety of cancer types. For example, it was revealed that the deletion of miR-210-3p may promote the carcinogenesis of renal cell carcinoma (18), while miR-210 is increased in osteosarcoma and may contribute to the malignant progression of the disease (19). Furthermore, in breast cancer, miR-210 may interact with F-box only protein 31 and regulate the proliferation and migration of human breast cancer cells (20).

In NSCLC, the upregulation of miR-210-3p has been demonstrated in several previous studies (21-23); however, the role of miR-210-3p in the pathogenesis NSCLC requires further investigation. The aim of the present study was to investigate the expression and biological functions of miR-210-3p in NSCLC, and to elucidate the underlying molecular mechanisms in NSCLC. The expression of miR-210-3p in NSCLC tumor tissues and cell lines was examined, and the associations between the expression of miR-210-3p and the clinical features of patients with NSCLC were investigated. Furthermore, the effect of miR-210-3p on cell proliferation and apoptosis was explored.

\section{Materials and methods}

Patients and clinical information. The present study enrolled 30 patients (Average age 62.1 \pm 9.8 years, Age range, 35-79 years; 18 males and 12 females) who had been diagnosed with NSCLC between August 2010 and December 2015 at Handan First Hospital (Handan, China). For each patient, paired cancer tissues and adjacent normal tissues were collected during surgery and immediately stored in liquid nitrogen until use. Patients who received chemotherapy or radiotherapy were excluded from the study. The clinical information of the patients is summarized in Table I. The Research Ethics Committee of Handan First Hospital approved the present study, and each patient signed an informed consent form.

Cell culture. The human NSCLC cell lines A549, H358, H1650 and H1299, and normal human lung epithelial cell line BEAS-2B, were purchased from the Shanghai Institute of Cell Biology, Chinese Academy of Sciences (Shanghai, China). Cells were maintained in Dulbecco's modified Eagle's medium (DMEM) supplemented with $10 \%$ fetal bovine serum (FBS) (both Gibco; Thermo Fisher Scientific, Inc., Waltham, MA, USA) and 1\% penicillin/streptomycin solution (Sigma-Aldrich; Merck KGaA, Darmstadt, Germany) in an incubator at $37^{\circ} \mathrm{C}$ with $5 \% \mathrm{CO}_{2}$.

Cell transfection. The miR-210-3p inhibitors (5'-UCAGCC GCUGUCACACGCACAG-3'; $50 \mathrm{nM}$ ), miR-210-3p inhibitor negative control (NC; 5'-CAGUACUUUUGUGUAGUA CAA-3'; $50 \mathrm{nM}$ ) and SIN3A small interfering (si)RNA (20 nM; forward, 5'-CUACGUCUCAAGGAACCUTT-3' and reverse 5'-UAGGUUCCUUGAGACGUAGTT-3') were synthesized by Shanghai GenePharma Co., Ltd., (Shanghai, China). The sequences of the SIN3A siRNA were: Cell transfection was performed using Lipofectamine ${ }^{\circledR}$ RNAi Max (Invitrogen; Thermo Fisher Scientific, Inc.). Cells were divided into five groups: Control group (untreated cells), NC group (miR-210-3p inhibitor NC-transfected group), inhibitor group (miR-210-3p inhibitor-transfected group), inhibitor + SIN3A siRNA group (miR-210-3p inhibitor + SIN3A siRNA-transfected group), NC + SIN3A siRNA group (miR-210-3p inhibitor NC + SIN3A siRNA-transfected group). The effects of the miR-210-3p inhibitor on A549 or H1299 cells were examined using various assays at $48 \mathrm{~h}$ after transfection.

Cell proliferation analysis. The effects of the miR-210-3p inhibitor on the proliferation of A549 and H1299 cells was determined by using an MTT assay (the purple formazan was dissolved in DMSO) at 12, 24 and $48 \mathrm{~h}$, as well as a Cell Proliferation kit I (MTT; Sigma-Aldrich; Merck KGaA), according to the manufacturer's protocol. Viability was determined by the optical density values at $490 \mathrm{~nm}$.

Cell apoptosis analysis. After transfection for 48 h, A549 and H1299 cells were double-stained with annexin V-fluorescein isothiocyanate (FITC) at $4^{\circ} \mathrm{C}$ for $15 \mathrm{~min}$ and propidium iodide (PI) and at $4^{\circ} \mathrm{C}$ for 5 min using a PI/Annexin V-FITC Apoptosis Detection kit (Sigma-Aldrich; Merck KGaA). The rates of apoptosis of the cells in different groups were examined with a BD FACSCalibur ${ }^{\mathrm{TM}}$ flow cytometer (BD Biosciences, San Jose, CA, USA). The data was analyzed using FlowJo (version 7.6.5; Tree Star, Inc., Ashland, OR, USA).

Reverse transcription-quantitative polymerase chain reaction (RT-qPCR). Total RNA was extracted from cells and the tissue samples using TRIzol ${ }^{\circledR}$ (Invitrogen; Thermo Fisher Scientific, Inc.) and RT-qPCR was performed. The expression of miR-210-3p was examined using a Hairpin-it ${ }^{\mathrm{TM}}$ MicroRNA Quantitation kit (Shanghai GenePharma Co., Ltd.), with U6 (RNU6B; Shanghai GenePharma Co., Ltd.) used for normalization. The thermocycling profiles were as follow: $95^{\circ} \mathrm{C}$ for $3 \mathrm{~min}$; followed by 40 cycles of $95^{\circ} \mathrm{C}$ for $12 \mathrm{sec}$ and $62^{\circ} \mathrm{C}$ for $40 \mathrm{sec}$. The data were analyzed using the $2^{-\Delta \Delta \mathrm{Cq}}$ method (24). The mRNA expression levels of SIN3A were examined by performing reverse transcription with a PrimeScript ${ }^{\mathrm{TM}} \mathrm{RT}$ Master Mix (Takara Biotechnology Co., Ltd., Dalian, China) at $37^{\circ} \mathrm{C}$ for $15 \mathrm{~min}$. PCR was performed using a $\mathrm{SYBR}^{\circledR}$ Fast qPCR Mix (Takara Biotechnology Co., Ltd.), with GAPDH for normalization. RT-qPCR was conducted on an ABI 7500 Real-Time PCR System (Applied Biosystems; Thermo Fisher Scientific, Inc.), according to the manufacturer's protocol. The primer sequences were as follows: miR-210-3p forward, 5'-GTGCAGGGTCCGAGGT-3' and reverse, 5'-TATCTG TGCGTGTGACAGCGGCT-3'; U6 forward, 5'-CTCGCT TCGGCAGCACA-3' and reverse, 5'-AACGCTTCACGA ATTTGCGT-3'; SIN3A forward, 5'-TTAAATCTCAGAGCA TCGACAC-3' and reverse, 5'-AGGAGTTGTCACATTCAC CA-3'; GAPDH forward, 5'-CATTTCCTGGTATGACAA CGA-3' and reverse, 5'-GTCTACATGGCAACTGTGAG-3'. The thermocycling profiles were as follows: $95^{\circ} \mathrm{C}$ for $30 \mathrm{sec}$; followed by 40 cycles of $95^{\circ} \mathrm{C}$ for $5 \mathrm{sec}$ and $60^{\circ} \mathrm{C}$ for $30 \mathrm{sec}$. The data were analyzed using the $2^{-\Delta \Delta \mathrm{Cq}}$ method. 
Table I. Univariate analysis for correlation between the expression levels of miR-210-3p and the clinical characteristics of the patients.

\begin{tabular}{lcc}
\hline Characteristics & $\mathrm{n}$ & Relative miR-210-3p expression level \\
\hline Age, years & 11 & \\
$\quad<60$ & 19 & $1.29 \pm 0.83$ \\
$\geq 60$ & & $1.37 \pm 1.07$ \\
Sex & 18 & \\
$\quad$ Male & 12 & $1.39 \pm 0.76$ \\
Female & & $1.21 \pm 0.98$ \\
Tumor size, cm & 9 & $1.52 \pm 1.29$ \\
$\geq 5$ & 21 & $1.10 \pm 0.82$ \\
$<5$ & & \\
Histological grade (differentiation) & 14 & $1.31 \pm 0.97$ \\
Well-intermediate & 16 & $1.12 \pm 1.12$ \\
Poor & & \\
Metastasis & 8 & $1.49 \pm 1.05$ \\
$\quad$ Yes & 22 & $1.14 \pm 0.74$ \\
No & & 0.005 \\
\hline
\end{tabular}

miR-210-3p, microRNA-210-3p.

Western blot analysis. A549 cells were harvested at $48 \mathrm{~h}$ after transfection and lysed with radioimmunoprecipitation assay buffer (Beyotime Institute of Biotechnology, Shanghai, China). The concentration of the total protein was determined using a BCA Protein Assay kit (Beyotime Institute of Biotechnology). Subsequently, $8 \%$ SDS-PAGE gel was used to separate the proteins, which were then transferred to polyvinylidene difluoride membranes and blocked with $5 \%$ non-fat milk at room temperature for $1 \mathrm{~h}$. Subsequently, the membranes were incubated overnight at $4^{\circ} \mathrm{C}$ with the following primary antibodies $(1: 1,000)$ obtained from Wuhan Boster Biological Technology, Ltd. (Wuhan, China): Anti-SIN3A (cat. no. BM5270), anti-B-cell lymphoma 2 (Bcl-2; cat. no. A00040-1), anti-Caspase-3 (cat. no. BM3957) and anti-GAPDH (cat. no. A00227). The following day, the membranes were incubated with horseradish peroxidaseconjugated secondary antibodies (cat. no. A0208, 1:1,000; Beyotime Institute of Biotechnology) at room temperature for 45 min and treated with BeyoECL Plus enhanced chemiluminescent reagent (Beyotime Institute of Biotechnology). The signals were detected and imaged using a ChemiDoc ${ }^{\mathrm{TM}} \mathrm{XRS}^{+}$ system (Bio-Rad Laboratories, Inc., Hercules, CA, USA) and analyzed by using ImageJ software (version 1.47 ; NIH, Bethesda, MD, USA).

Dual-luciferase reporter assay. The prediction of the targets of miR-210-3p was performed using bioinformatics tools (TargetScan) as previously described (25). The wild-type SIN3A 3' untranslated region (UTR; SIN3A-3'UTR), which contains the miR-210-3p binding site, and a mutant SIN3A 3'UTR sequence (SIN3A-MUT) were cloned into p-MIR-reporter plasmids (Thermo Fisher Scientific, Inc.) and transfected into A549 cells with miR-210-3p mimics (synthesized by Shanghai
GenePharma Co., Ltd.; 50 nM; sense, 5'-CUGUGCGUGUGA CAGCGGCUGA-3'; antisense, 5'-AGCCGCUGUCACACG CACAGUU-3') or a mimic NC (50 nM; sense, 5'-UUCUCC GAACGUGUCACGUTT-3'; antisense, 5'-ACGUGACAC GUUCGGAGAATT-3') using Lipofectamine ${ }^{\circledR}$ RNAi Max. Cells were collected $48 \mathrm{~h}$ after transfection, and the activities of the luciferases were detected using a Dual-Luciferase Reporter Assay kit (Beyotime Institute of Biotechnology). The activity of firefly luciferase was normalized to that of renilla luciferase.

Statistical analysis. All statistical analysis was performed using SPSS v. 22.0 (IBM Corp., Armonk, NY, USA). Data were presented as the mean \pm standard deviation of three repeated experiments. The differences between the expression levels of miR-210-3p and SINA3 in the paired tumor tissues and adjacent tissues were analyzed using a paired Student's $\mathrm{t}$-test, while the differences among multiple groups for in vitro studies were analyzed using one-way analysis of variance followed by a Turkey's post hoc test. Pearson's correlation coefficient was used for correlation analysis. Cox regression model was applied for univariate analysis. $\mathrm{P}<0.05$ was considered to indicate a statistically significant difference.

\section{Results}

Comparison of the expression of miR-210-3p in tissue samples and cell lines. Initially, paired lung cancer tissues and adjacent normal tissues were collected from 30 patients with NSCLC, and the levels of miR-210-3p in the different tissues were examined using RT-qPCR (Fig. 1). The expression of miR-210-3p was significantly increased in the cancer tissues compared with the level in the adjacent tissues $(\mathrm{P}<0.01$; Fig. 1A). The 

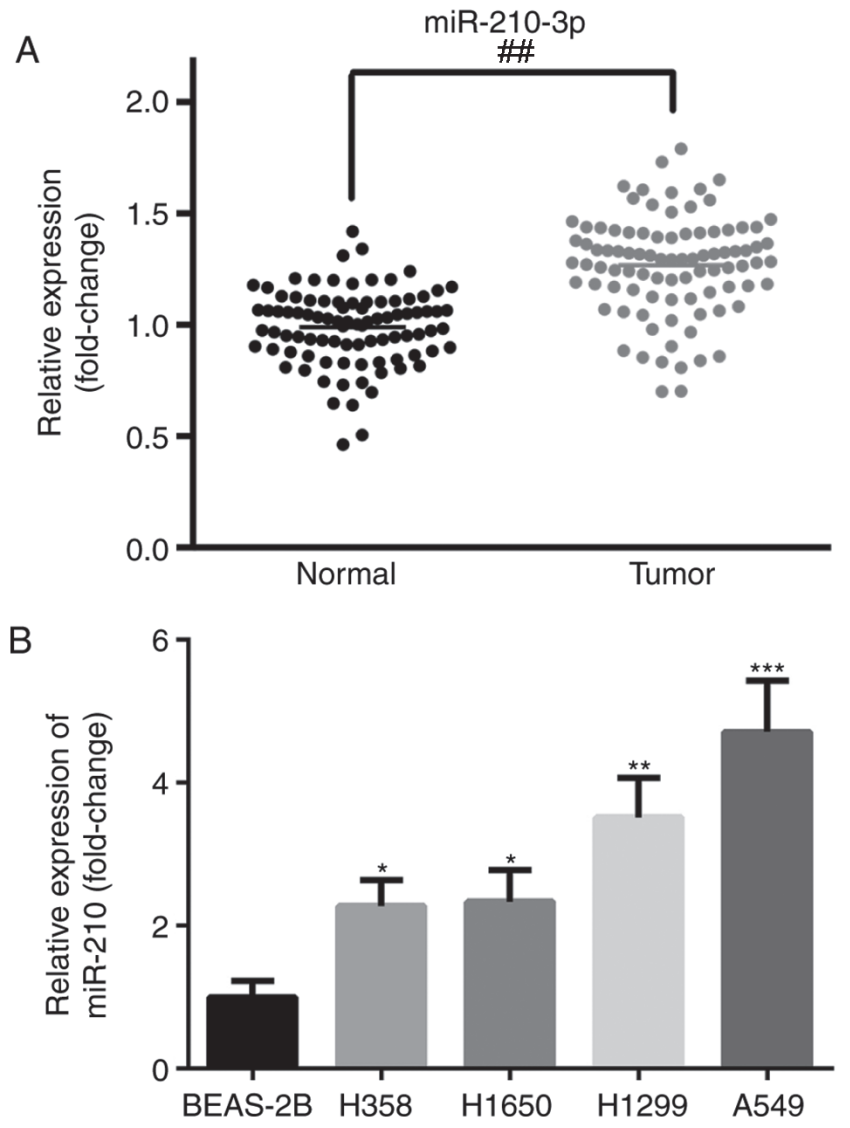

Figure 1. miR-210-3p is upregulated in NSCLC. (A) Expression level of miR-210-3p in lung cancer tissues and adjacent tissues. (B) Expression level of miR-210-3p in various NSCLC cell lines and a normal human lung epithelial cell line, BEAS-2B. ${ }^{\# \#} \mathrm{P}<0.01 ;{ }^{*} \mathrm{P}<0.05,{ }^{* *} \mathrm{P}<0.01$ and ${ }^{* * *} \mathrm{P}<0.001$ vs. the BEAS-2B cell line. miR-210-3p, microRNA-210-3p; NSCLC, non-small cell lung cancer.

expression level of miR-210-3p was positively correlated with tumor size $(\mathrm{P}=0.005)$, histological grade $(\mathrm{P}=0.024)$ and metastasis $(\mathrm{P}=0.011)$ (Table I). Furthermore, the expression levels of miR-210-3p in four NSCLC cell lines (A549, H358, H1650, H1299) and a normal human lung epithelial cell line (BEAS-2B) were also examined. As demonstrated in Fig. 1B, the expression of miR-210-3p was significantly increased in NSCLC cell lines compared with the level in the BEAS-2B cell line $(\mathrm{P}<0.05)$. A549 and H1299 exhibited the highest expression of miR-210-3p and as such were utilized for further analysis.

Effect of transient miR-210-3p knockdown on the proliferation and apoptosis of A549 and H1299 cells in vitro. To further explore the roles of miR-210-3p in the pathogenesis of NSCLC, A549 and H1299 cells were cultured and transfected with miR-210-3p inhibitors or inhibitor NCs, and the effects of miR-210-3p on the proliferation and apoptosis of A549 cells were examined using an MTT assay and flow cytometry, respectively. The transient downregulation of miR-210-3p in the inhibitor group significantly suppressed the cell growth at 24 and $48 \mathrm{~h}$ after transfection, as compared with the control group $(\mathrm{P}<0.01$; Fig. 2$)$. Furthermore, the results of the flow cytometry analysis indicated that transfection of A549 and H1299 cells with miR-210-3p inhibitors induced a marked
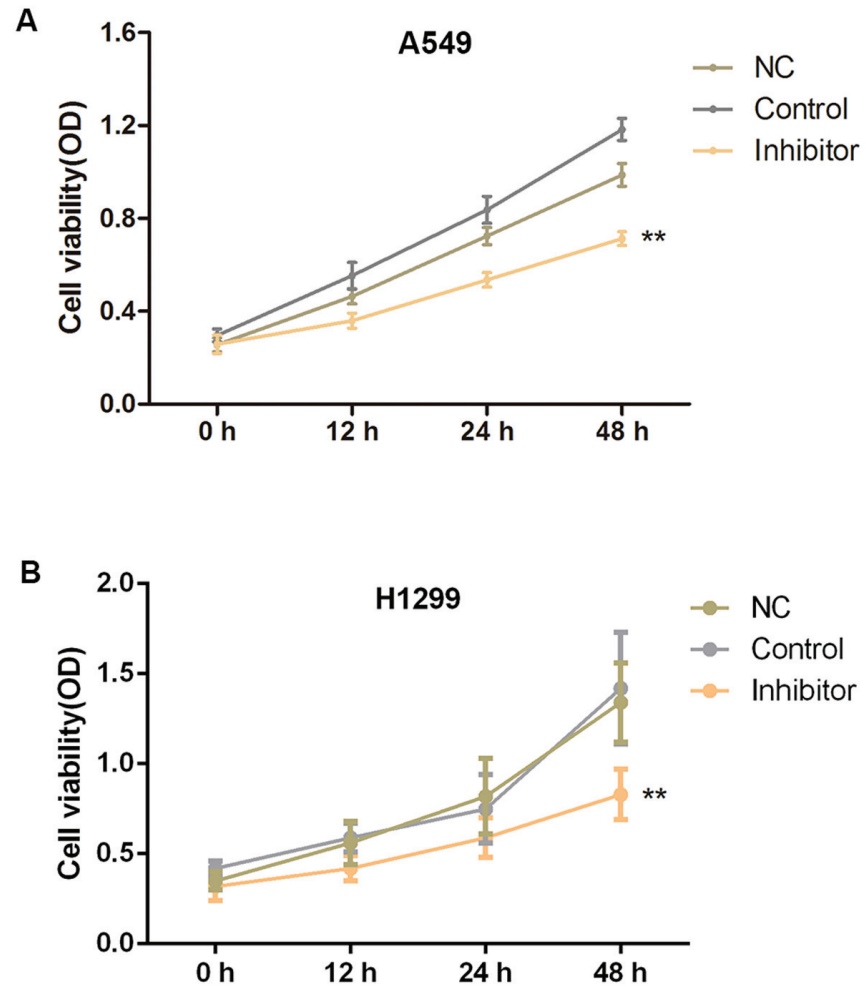

Figure 2. Knockdown of miR-210-3p decreases the proliferation of non-small cell lung cancer cell lines at $48 \mathrm{~h}$. Effect of transient knockdown of miR-210-3p on the proliferation of (A) A549 and (B) H1299 cells in vitro. ${ }^{* * *} \mathrm{P}<0.01$ vs. the control group. miR-210-3p, microRNA-210-3p; NC, negative control; OD, optical density.

increase in the rate of cell apoptosis in vitro, as compared with the level in the control group $(\mathrm{P}<0.01$; Fig. 3$)$.

SIN3A is a direct target of miR-210-3p in NSCLC. Using bioinformatics tools (TargetScan (25). SIN3A was predicted as a target of miR-210-3p. Therefore, the association between miR-210-3p and SIN3A in the pathogenesis of NSCLC was explored. The expression level of SIN3A was demonstrated to be significantly decreased in lung cancer tissues compared with the level in the paired adjacent tissues $(\mathrm{P}<0.01$; Fig. 4A), and the expression level of miR-210-3p was negatively correlated with that of SIN3A ( $r=-0.273 ; \mathrm{P}=0.009$; Fig. 4B).

Knockdown of miR-210-3p induced a significant decrease in the expression level of miR-210-3p and a significant increase in the expression of SIN3A in A549 and H1299 cells at the mRNA and protein levels, when compared with the control group ( $\mathrm{P}<0.05$; Figs. 5 and 6). Furthermore, compared with the control group, knockdown of miR-210-3p significantly decreased the expression level of the anti-apoptotic factor $\mathrm{Bcl}-2$ and increased the expression of the pro-apoptotic factor Caspase-3 ( $\mathrm{P}<0.05$; Fig. 6B and $\mathrm{C}$ ). On the other hand, co-transfection with miR-210-3p inhibitor and SIN3A siRNA partially blocked the miR-210-3p inhibitor-induced pro-apoptotic effects (Fig. 7). Co-transfection with miR-210-3p NC and SIN3A siRNA further reduced the expression of SIN3A $(\mathrm{P}<0.05)$, when compared with the NC group, increased the proliferation and inhibited the apoptosis of A549 cells (but with no significant difference compared with control; $\mathrm{P}>0.05)$. 

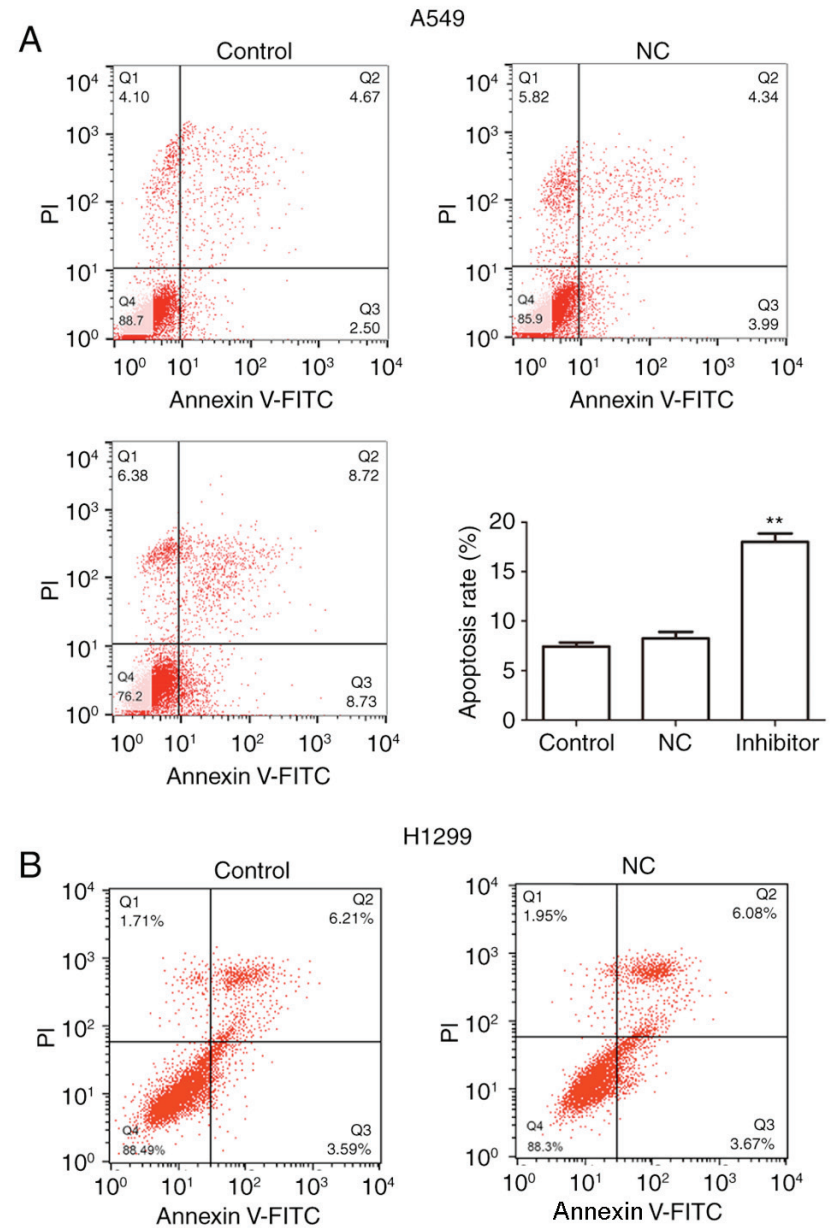

$\mathrm{H} 1299$
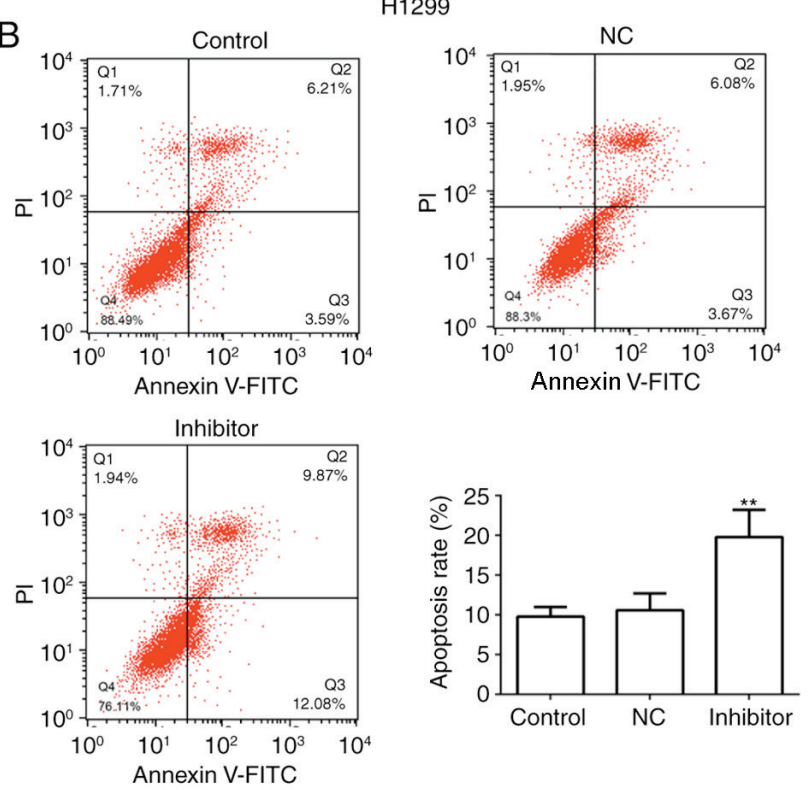

Figure 3. Knockdown of miR-210-3p increases the apoptosis rate of non-small cell lung cancer cell lines. Effect of transient knockdown of miR-210-3p on the apoptosis of (A) A549 and (B) $\mathrm{H} 1299$ cells in vitro. ${ }^{* *} \mathrm{P}<0.01$ vs. the control group. miR-210-3p, microRNA-210-3p; NC, negative control; PI, propidium iodide; FITC, fluorescein isothiocyanate.

Finally, a dual-luciferase reporter assay was used to investigate whether miR-210-3p directly targets SIN3A. It was revealed that transfection of the cells with miR-210-3p mimics significantly suppressed the luciferase activity of the SIN3A-3'UTR reporter compared with the activity in the NC $(\mathrm{P}<0.01)$; whereas miR-210-3p mimics had no significant effect on cells transfected with the SIN3A-MUT reporter (Fig. 8). These results suggest that miR-210-3p directly targets the 3'UTR of SIN3A.

\section{Discussion}

The roles of miR-210 in various cancer types have been discussed in numerous previous studies. miR-210 has been
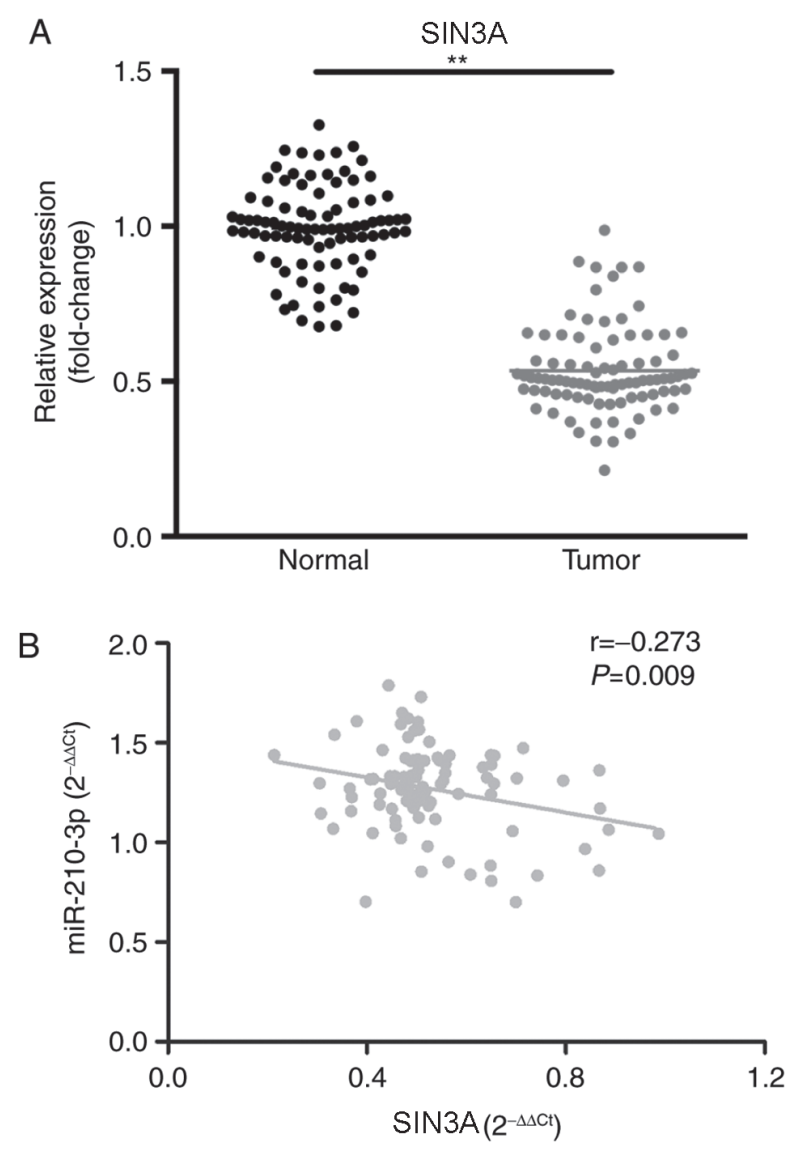

Figure 4. SIN3A expression levels are decreased in NSCLC. (A) Expression levels of SIN3A in lung cancer tissues and the adjacent tissues. (B) Correlation between the expression level of miR-210-3p and SIN3A in lung cancer tissues. ${ }^{* * *} \mathrm{P}<0.01$ vs. the normal group. miR-210-3p, microRNA-210-3p.

demonstrated to be upregulated in the majority of cancer types, including pancreatic cancer $(26,27)$, colorectal cancer $(28,29)$, breast cancer (30-32) and renal cell carcinoma (33-35), suggesting that it may act as an oncomiR. The roles of miR-210 in lung cancer have also been discussed previously. Zhang et al (36) reported that miR-210 was upregulated in the plasma of patients with early-stage NSCLC, suggesting that miR-210 has the potential to be a biomarker for the early diagnosis of NSCLC that may be detected by non-invasive techniques. Eilertsen et al (21) demonstrated that the expression of miR-210 in stromal cells and cancer cells may serve as a prognostic marker in NSCLC, and Li et al (37) suggested that the serum levels of miR-210 may serve as a diagnostic and prognostic marker for NSCLC. However, the majority of these studies have focused on the diagnostic and prognostic value of miR-210, and investigations into the effects of miR-210 on lung cancer cell behavior, including cell growth, apoptosis and migration, as well as the specific mechanisms underlying the role of miR-210 in the pathogenesis of NSCLC, have been limited. In the present study, increased miR-210-3p expression in cancer tissues and different NSCLC cell lines was observed, which was consistent with previous findings. Furthermore, knockdown of miR-210-3p in the A549 and H1299 lung cancer cell lines led to the significant suppression of cell proliferation and increase of cell apoptosis. These results suggest that 
A

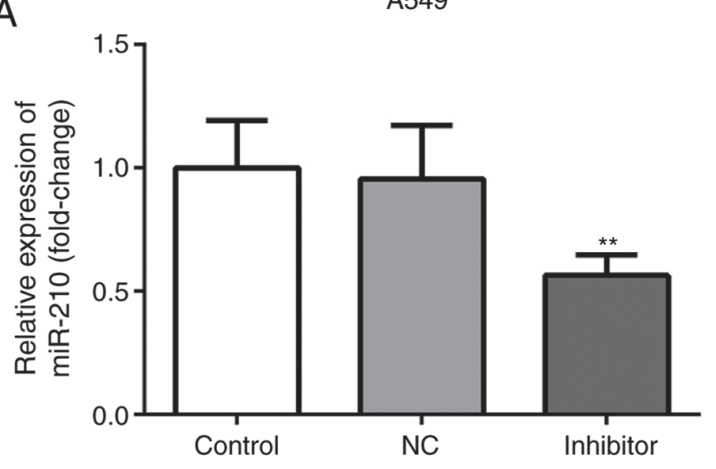

C

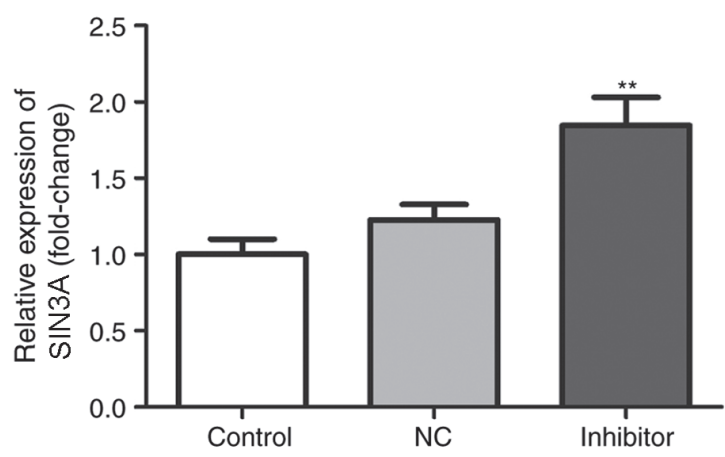

B

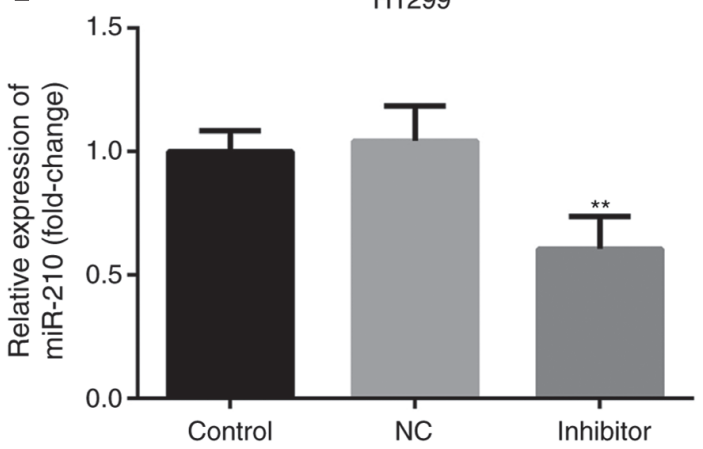

D

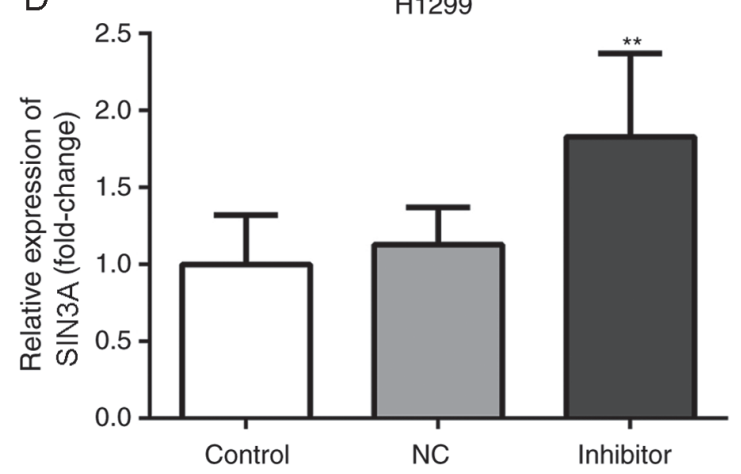

Figure 5. Knockdown of miR-210-3p decreases the mRNA expression of miR-210-3p and increases the mRNA expression of SIN3A in A549 and H1299 cells in vitro. Relative mRNA expression level of miR-210-3p in (A) A549 cells and (B) H1299 cells in the different groups. Relative mRNA expression level of SIN3A in (C) A549 cells and (D) H1299 cells in the different groups. ${ }^{* *} \mathrm{P}<0.01$ vs. the control group. miR-210-3p, microRNA-210-3p; NC, negative control.

A
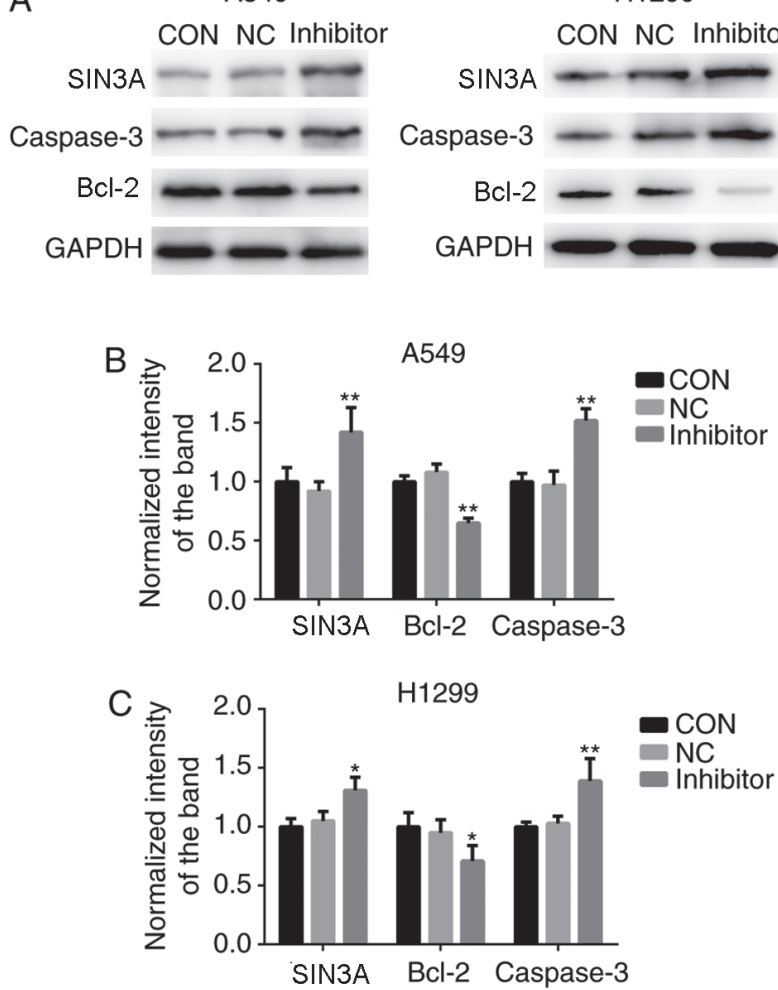

Figure 6. Effect of transient knockdown of miR-210-3p on the protein expression levels of SIN3A, Bcl-2 and Caspase-3. (A) Protein expression levels of SIN3A, Bcl-2 and Caspase-3 in the different groups in A549 and H1299 cells. Normalized intensities of the protein bands in (B) A549 and (C) H1229 cells. ${ }^{*} \mathrm{P}<0.05$ and ${ }^{* *} \mathrm{P}<0.01$ vs. the CON group. miR-210-3p, microRNA-210-3p; Bcl-2, B-cell lymphoma 2; NC, negative control; CON, control.
miR-210-3p is upregulated in NSCLC and that it may regulate the proliferation and apoptosis of lung cancer cells.

Using bioinformatics tools, SIN3A was predicted as a target gene of miR-210-3p; however, to the best of our knowledge, the association between miR-210-3p and SIN3A in NSCLC has not yet been discussed. SIN3A is a transcriptional regulator that contains a number of protein-interaction domains (38). Previous studies have indicated that SIN3A is involved in the processes of cell proliferation, apoptosis, differentiation and migration, as well as the regulation of the cell cycle and embryonic development, via interacting with certain proteins, including Myc, Myc-associated factor X, Max dimerization protein and methyl-CpG binding protein $2(39,40)$. Previous studies have identified SIN3A as a tumor suppressor in NSCLC. Suzuki et al (41) observed decreased expression of SIN3A in NSCLC, and Das et al (42) demonstrated that downregulation of SIN3A could increase the invasive behavior of A549 cells.

In the present study, a series of experiments were performed to explore the association between miR-210-3p and SIN3A in NSCLC. First, the expression levels of SIN3A in NSCLC tissues and adjacent normal tissues were compared, and it was revealed that SIN3A was downregulated in NSCLC, which was consistent with the results described by Suzuki et al (41). A subsequent correlation analysis indicated that the expression of SIN3A was significantly negatively correlated with the expression of miR-210-3p, suggesting that the upregulation of miR-210-3p may lead to inhibited expression of SIN3A in lung cancer tissues. The transfection of A549 and H1299 cells with an miR-210-3p inhibitor induced a significant increase in the expression of SIN3A, and also led to a significant decrease in 
A
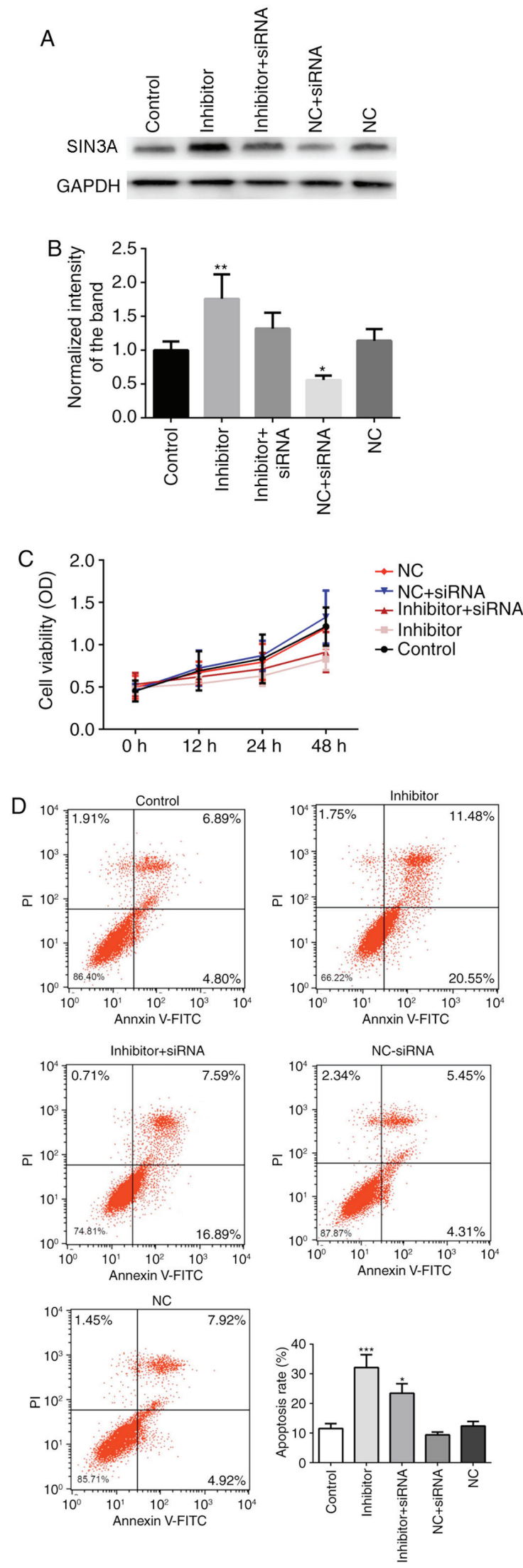

Figure 7. SIN3A siRNA partially blocks miR-210-3p inhibitor-induced pro-apoptotic effects in A549 cells. (A) Protein expression levels of SIN3A in the different groups in A549 cells. (B) Normalized intensities of the protein bands. (C) Proliferation of A549 cells in the different groups. (D) Apoptosis rate of cells in the different groups. ${ }^{*} \mathrm{P}<0.05,{ }^{* * *} \mathrm{P}<0.01$ and ${ }^{* * * *} \mathrm{P}<0.001$ vs. the control group. miR-210-3p, microRNA-210-3p; siRNA, small interfering RNA; NC, negative control; OD, optical density; PI, propidium iodide; FITC, fluorescein isothiocyanate.
A

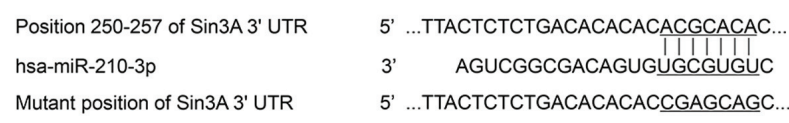

B

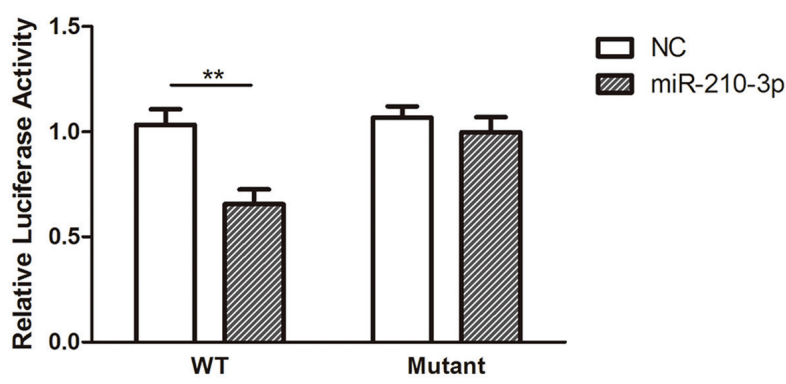

Figure 8. SIN3A is a direct target of miR-210-3p. (A) Sequence alignment of the binding site of the $3^{\prime}$ UTR of miR-210-3p and SIN3A. (B) Luciferase activity in the different groups following transfection. ${ }^{* *} \mathrm{P}<0.01 \mathrm{NC}$ vs. the miR-210-3p groups. miR-210-3p, microRNA-210-3p; UTR, untranslated region; WT, wild-type; $\mathrm{NC}$, negative control.

the expression of the downstream anti-apoptotic protein, Bcl-2, and an increase in the expression of the pro-apoptotic protein, Caspase-3. Furthermore, co-transfection with miR-210-3p inhibitor and SIN3A siRNA partially blocked miR-210-3p inhibitor-induced pro-apoptotic effects. Finally, a dual-luciferase reporter assay indicated that SIN3A is a direct target of miR-210-3p. As discussed, miR-210-3p may regulate the proliferation and apoptosis of A549 cells, and SIN3A is a key regulator of cell proliferation and apoptosis; thus, miR-210-3p may promote the proliferation and inhibit the apoptosis of lung cancer cells, at least partially, through targeting SIN3A.

The present study has limitations. First, due to ethical issues, only 30 clinical samples were included; therefore, the results should be verified with a larger sample size. Second, the present study includes only a clinical study and in vitro cell studies, and in vivo animal studies should also be performed to confirm the roles of miR-210-3p and SIN3A in NSCLC in the future.

In conclusion, the results of the present study indicate that miR-210-3p is upregulated in NSCLC and may regulate the proliferation and apoptosis of lung cancer cells by targeting SIN3A. These results may provide a novel therapeutic target for the treatment of NSCLC.

\section{Acknowledgements}

Not applicable.

\section{Funding}

No funding was received.

\section{Availability of data and materials}

The datasets used and/or analyzed during the current study are available from the corresponding author on reasonable request. 


\section{Authors' contributions}

XL and HD analyzed the patient data. LS performed histological examination of samples. JuZ and LZ performed some of the cell experiments. JR performed most of the cell experiments and he was a major contributor in writing the manuscript. JiZ designed the study and wrote part of the manuscript. All authors read and approved the final manuscript.

\section{Ethics approval and consent to participate}

The Research Ethics Committee of Handan First Hospital approved the present study. Each patient signed an informed consent form

\section{Patient consent for publication}

Not applicable.

\section{Competing interests}

The authors declare that they have no competing interests.

\section{References}

1. Li Z, Zhu W, Xiong L, Yu X, Chen X and Lin Q: Role of high expression levels of STK39 in the growth, migration and invasion of non-small cell type lung cancer cells. Oncotarget 7: 61366-61377, 2016.

2. Bernatsky S, Ramsey-Goldman R, Petri M, Urowitz MB, Gladman DD, Fortin PR, Yelin EH, Ginzler E, Hanly JG, Peschken C, et al: Smoking is the most significant modifiable lung cancer risk factor in systemic lupus erythematosus J Rheumatol 45: 393-396, 2018.

3. Fan J, Zhang W, Lei C, Qiao B, Liu Q, Chen Q, Jiao H, Jiang L, Cui S and Chen J: Vascular endothelial growth factor polymorphisms and lung cancer risk. Int J Clin Exp Med 8: 6406-6411, 2015.

4. Feng X, Qin JJ, Zheng BS, Huang LL, Xie XY and Zhou HF: Association of epidermal growth factor receptor (EGFR) gene polymorphism with lung cancer risk: A systematic review. J Recept Signal Transduct Res 34: 333-334, 2014

5. Higashi K, Ueda Y, Arisaka Y, Sakuma T, Nambu Y, Oguchi M, Seki H, Taki S, Tonami H and Yamamoto I: 18F-FDG uptake as a biologic prognostic factor for recurrence in patients with surgically resected non-small cell lung cancer. J Nucl Med 43: 39-45, 2002.

6. Wang J, Sheng Z, Yang W and Cai Y: Elevated serum concentration of chitinase 3-like 1 is an independent prognostic biomarker for poor survival in lung cancer patients. Cell Physiol Biochem 38: 461-468, 2016

7. Zhang Y, Li H, Han J and Zhang Y: Down-regulation of microRNA-124 is correlated with tumor metastasis and poor prognosis in patients with lung cancer. Int J Clin Exp Pathol 8: 1967-1972, 2015.

8. Hou J, Meng F, Chan LW, Cho WC and Wong SC: Circulating plasma MicroRNAs as diagnostic markers for NSCLC. Front Genet 7: 193, 2016

9. Kuribayashi K, Funaguchi $\mathrm{N}$ and Nakano T: Chemotherapy for advanced non-small cell lung cancer with a focus on squamous cell carcinoma. J Cancer Res Ther 12: 528-534, 2016.

10. Costa DF and Torchilin VP: Micelle-like nanoparticles as siRNA and miRNA carriers for cancer therapy. Biomed Microdevices 20: 59, 2018.

11. Marwitz S, Heinbockel L, Scheufele S, Kugler C, Reck M, Rabe KF, Perner S, Goldmann T and Ammerpohl O: Fountain of youth for squamous cell carcinomas? On the epigenetic age of non-small cell lung cancer and corresponding tumor-free lung tissues. Int J Cancer 143: 3061-3070, 2018.

12. Zheng $\mathrm{CH}$, Chen XM, Zhang FB, Zhao C and Tu SS: Inhibition of CXCR4 regulates epithelial mesenchymal transition of NSCLC via the Hippo-YAP signaling pathway. Cell Biol Int 42: 1386-1394, 2018.
13. Takahashi Y, Sakaguchi K, Horio H, Hiramatsu K, Moriya S, Takahashi K and Kawakita M: Urinary N1, N12-diacetylspermine is a non-invasive marker for the diagnosis and prognosis of non-small-cell lung cancer. Br J Cancer 113: 1493-1501, 2015.

14. Luo C, Tetteh PW, Merz PR, Dickes E, Abukiwan A, Hotz-Wagenblatt A, Holland-Cunz S, Sinnberg T, Schittek B, Schadendorf D, et al: miR-137 inhibits the invasion of melanoma cells through downregulation of multiple oncogenic target genes. J Invest Dermatol 133: 768-775, 2013.

15. Jing XG, Chen TF, Huang C, Wang H, An L, Cheng $Z$ and Zhang GJ: MiR-15a expression analysis in non-small cell lung cancer A549 cells under local hypoxia microenvironment. Eur Rev Med Pharmacol Sci 21: 2069-2074, 2017.

16. Ning T, Peng Z, Li S, Qu Y, Zhang H, Duan J, Wang X, Yang H, Liu R, Deng T, et al: miR-455 inhibits cell proliferation and migration via negative regulation of EGFR in human gastric cancer. Oncol Rep 38: 175-182, 2017.

17. Ning T, Zhang H, Wang X, Li S, Zhang L, Deng T, Zhou L, Liu R, Wang X, Bai M, et al: miR-370 regulates cell proliferation and migration by targeting EGFR in gastric cancer. Oncol Rep 38: 384-392, 2017.

18. Yoshino H, Yonemori M, Miyamoto K, Tatarano S, Kofuji S, Nohata N, Nakagawa M and Enokida H: microRNA-210-3p depletion by CRISPR/Cas9 promoted tumorigenesis through revival of TWIST1 in renal cell carcinoma. Oncotarget 8: 20881-20894, 2017.

19. Zhang H, Mai Q and Chen J: MicroRNA-210 is increased and it is required for dedifferentiation of osteosarcoma cell line. Cell Biol Int 41: 267-275, 2017.

20. Liu D, Xia H, Wang F, Chen $\mathrm{C}$ and Long J: MicroRNA-210 interacts with $\mathrm{FBXO} 31$ to regulate cancer proliferation cell cycle and migration in human breast cancer. Onco Targets Ther 9: 5245-5255, 2016.

21. Eilertsen M, Andersen S, Al-Saad S, Richardsen E, Stenvold H, Hald SM, Al-Shibli K, Donnem T, Busund LT and Bremnes RM: Positive prognostic impact of miR-210 in non-small cell lung cancer. Lung Cancer 83: 272-278, 2014.

22. Puisségur MP, Mazure NM, Bertero T, Pradelli L, Grosso S, Robbe-Sermesant K, Maurin T, Lebrigand K, Cardinaud B, Hofman V, et al: miR-210 is overexpressed in late stages of lung cancer and mediates mitochondrial alterations associated with modulation of HIF-1 activity. Cell Death Differ 18: 465-478, 2011.

23. Zhu W, Zhou K, Zha Y, Chen D, He J, Ma H, Liu X, Le H and Zhang Y: Diagnostic value of serum miR-182, miR-183, miR-210, and miR-126 levels in patients with early-stage non-small cell lung cancer. PLoS One 11: e0153046, 2016.

24. Livak KJ and Schmittgen TD: Analysis of relative gene expression data using real-time quantitative PCR and the 2(-Delta Delta C(T)) method. Methods 25: 402-408, 2001.

25. Agarwal V, Bell GW, Nam JW and Bartel DP: Predicting effective microRNA target sites in mammalian mRNAs. Elife 4 2015.

26. Takikawa T, Masamune A, Hamada S, Nakano E, Yoshida N and Shimosegawa T: miR-210 regulates the interaction between pancreatic cancer cells and stellate cells. Biochem Biophys Res Commun 437: 433-439, 2013.

27. Yu Q, Xu C, Yuan W, Wang C, Zhao P, Chen L and Ma J: Evaluation of plasma MicroRNAs as diagnostic and prognostic biomarkers in pancreatic adenocarcinoma: miR-196a and miR-210 could be negative and positive prognostic markers, respectively. Biomed Res Int 2017: 6495867, 2017.

28. Qu A, Du L, Yang Y, Liu H, Li J, Wang L, Liu Y, Dong Z, Zhang X, Jiang X, et al: Hypoxia-inducible MiR-210 is an independent prognostic factor and contributes to metastasis in colorectal cancer. PLoS One 9: e90952, 2014.

29. Wang W, Qu A, Liu W, Liu Y, Zheng G, Du L, Zhang X, Yang Y, Wang $\mathrm{C}$ and Chen X: Circulating miR-210 as a diagnostic and prognostic biomarker for colorectal cancer. Eur J Cancer Care (Engl) 26, 2017.

30. Bar I, Merhi A, Abdel-Sater F, Ben Addi A, Sollennita S, Canon JL and Delrée P: The MicroRNA miR-210 is expressed by cancer cells but also by the tumor microenvironment in triple-negative breast cancer. J Histochem Cytochem 65: 335-346, 2017.

31. Shidfar A, Costa FF, Scholtens D, Bischof JM, Sullivan ME, Ivancic DZ, Vanin EF, Soares MB, Wang J and Khan SA: Expression of miR-18a and miR-210 in normal breast tissue as candidate biomarkers of breast cancer risk. Cancer Prev Res (Phila) 10: 89-97, 2017. 
32. Tang Y, Zhou X, Ji J, Chen L, Cao J, Luo J and Zhang S: High expression levels of miR-21 and miR-210 predict unfavorable survival in breast cancer: A systemic review and meta-analysis. Int J Biol Markers 30: e347-e358, 2015.

33. Fedorko M, Stanik M, Iliev R, Redova-Lojova M, Machackova T, Svoboda M, Pacik D, Dolezel J and Slaby O: Combination of MiR-378 and MiR-210 serum levels enables sensitive detection of renal cell carcinoma. Int J Mol Sci 16: 23382-23389, 2015.

34. Redova M, Poprach A, Besse A, Iliev R, Nekvindova J, Lakomy R, Radova L, Svoboda M, Dolezel J, Vyzula R and Slaby O: MiR-210 expression in tumor tissue and in vitro effects of its silencing in renal cell carcinoma. Tumour Biol 34: 481-491, 2013.

35. Samaan S, Khella HW, Girgis A, Scorilas A, Lianidou E, Gabril M, Krylov SN, Jewett M, Bjarnason GA, El-said H and Yousef GM: miR-210 is a prognostic marker in clear cell renal cell carcinoma. J Mol Diagn 17: 136-144, 2015.

36. Zhang H, Mao F, Shen T, Luo Q, Ding Z, Qian L and Huang J: Plasma miR-145, miR-20a, miR-21 and miR-223 as novel biomarkers for screening early-stage non-small cell lung cancer. Oncol Lett 13: 669-676, 2017.

37. Li ZH, Zhang H, Yang ZG, Wen GQ, Cui YB and Shao GG: Prognostic significance of serum microRNA-210 levels in nonsmall-cell lung cancer. J Int Med Res 41: 1437-1444, 2013.
38. Bansal N, Bosch A, Leibovitch B, Pereira L, Cubedo E, Yu J, Pierzchalski K, Jones JW, Fishel M, Kane M, et al: Blocking the PAH2 domain of Sin3A inhibits tumorigenesis and confers retinoid sensitivity in triple negative breast cancer. Oncotarget 7: 43689-43702, 2016.

39. Lewis MJ, Liu J, Libby EF, Lee M, Crawford NP and Hurst DR: SIN3A and SIN3B differentially regulate breast cancer metastasis. Oncotarget 7: 78713-78725, 2016.

40. Solaimani P, Wang F and Hankinson O: SIN3A, generally regarded as a transcriptional repressor, is required for induction of gene transcription by the aryl hydrocarbon receptor. J Biol Chem 289: 33655-33662, 2014.

41. Suzuki H, Ouchida M, Yamamoto H, Yano M, Toyooka S, Aoe M, Shimizu N, Date H and Shimizu K: Decreased expression of the SIN3A gene, a candidate tumor suppressor located at the prevalent allelic loss region $15 \mathrm{q} 23$ in non-small cell lung cancer. Lung Cancer 59: 24-31, 2008.

42. Das TK, Sangodkar J, Negre N, Narla G and Cagan RL: Sin3a acts through a multi-gene module to regulate invasion in Drosophila and human tumors. Oncogene 32: 3184-3197, 2013.

This work is licensed under a Creative Commons Attribution-NonCommercial-NoDerivatives 4.0 International (CC BY-NC-ND 4.0) License. 